Introduction RCS exposure remains a major concern both in developed and developing countries. A recent assessment estimated that about 440000 deaths from cancer attributable to RCS exposure will occur in Europe alone, from 2010 to 2069; the burden and loss of life in economically developing countries is anticipated to be even more bleak. Unless exposure to RCS is controlled, many hundreds of thousands of lives will be lost from silicosis, silico-tuberculosis, chronic obstructive pulmonary disease and lung cancer.

One aim of the international non-profit organisation, Workplace Health Without Borders (WHWB, www.whwb.org), is to build expertise in preventing workplace disease and injury worldwide. There is a wealth of experience amongst the WHWB membership in assessing the health risk and controlling exposures to RCS. Information shared through WHWB can be leveraged in economically developing countries to expedite the reduction of the unacceptably high risk of lung disease by preventing exposures.

Methods An overview of the global silica problem will be presented using the latest epidemiological literature as a reference; also a snapshot of learnings, good practices from WHWB presentations, training, and control initiatives such as those provided for agate workers in India. Learnings from research carried out in Queensland, Australia will be shared, to facilitate improvement in RCS exposure reduction, internationally.

Results WHWB is considered as an 'information hub' and 'conduit of good practices'. Through its membership, collaborations can be developed to expedite good practices, which in turn can be shared globally. Additionally, the WHWB initiatives in reducing exposures to RCS align well with the ongoing WHO efforts to document the number of silicosis cases, worldwide.

Discussion WHWB is working collaboratively to focus its efforts while avoiding duplication, especially in underserved populations and for informal work groups and communities. Partners who work closely with WHWB on RCS education and exposure control include OHTA and the University of Toronto, amongst others.

\section{C GLOBAL IMPACT: WHWB-US MODEL OF INCREASING PROFESSIONAL OUTREACH AND GROWTH}

${ }^{1}$ DF Goldsmith*, ${ }^{2} \mathrm{M}$ O'Reilly. ${ }^{1}$ George Washington University, Washington DC, USA; ${ }^{2}$ State University of New York, Albany NY, USA

\subsection{6/oemed-2018-ICOHabstracts.664}

Problem WHWB-US is an independent affiliate of WHWB. Many of our founding members are sensitive to global issues because of occupational health risks encountered during their work in other countries. There is a limited number of US industrial hygienists with global perspectives and, therefore, we need to develop a strategy that will increase our membership. We believe our approach may offer a blueprint for occupational hygienists in similar situations throughout the world.

Possible solutions As WHWB-US grows, we wish to establish student chapters and to reach out to other professionals in fields such as engineering, public health, medicine, and business. WHWB-US chose Ann Arbour as its headquarters because the University of Michigan's (UMich) Industrial Hygiene (IH) program has a strong global orientation. This led to the establishment of our first UMich student chapter in
2016. We are in the process of establishing student chapters at Brigham Young University in Utah and Idaho and George Washington University in Washington DC. Student members have worked with the electronics industry in Mexico, the ewaste industry in Thailand and the Vietnamese-American community in nail salons. We hope to add members by encouraging interested professionals from business, unions, consumer groups, physicians, and safety disciplines to join WHWB-US. We expect that lessons learned from these efforts will be scalable to global problems.

Going forward WHWB-US is urging the involvement of graduate students and their faculty in medicine, public health, environmental epidemiology, engineering, $\mathrm{IH}$ and business to participate in the 2018 IOHA Conference in Washington DC. New members will contribute to WHWB-US growth, and these younger professionals will be encouraged to join in leadership and recruitment efforts.

Conclusion We feel this approach will enable WHWB-US to expand its membership and offer a model for other practitioners from outside the US to join WHWB International and develop their own chapters and professional collaborations.

\section{$1610 \mathrm{~d}$ OCCUPATIONAL HEALTH AND SAFETY WORKFORCE DEVELOPMENT IN MOZAMBIQUE}

${ }^{1}$ SM Thygerson*, ${ }^{2}$ CV Muianga. ${ }^{1}$ Department of Health Science, Brigham Young University, Provo, Utah, USA; ${ }^{2}$ Centre for Industrial Studies, Safety and Environment (CEISA), Eduardo Mondlane University, Maputo, Mozambique (in leave of absence)

\subsection{6/oemed-2018-ICOHabstracts.665}

Background Integrated and collaborative efforts between stakeholders, including Government, private sector, labour unions, academic and research institutions, and other national and international NGOs in Mozambique, are working to improve occupational safety and health (OSH) conditions. Although the International Organisation of Work has adopted international $\mathrm{OSH}$ development recommendations and competencies to improve specific $\mathrm{OSH}$ training and education, this practice has yet to be implemented.

Objectives This study examined the Mozambican national education and training system for OSH workforce development (both higher education students and continuing education of workers).

Methods A literature review included government documents and reports about technical and professional education. Primary data was collected using surveys and interviews of the principal leaders in OSH (General Inspector of Work, Departments of Education and higher education institutions).

Results In 2009, none of the 14 functioning public higher education institutions had a complete degree course in OSH. Currently, the OSH capacity has greatly improved, particularly due to the increased international mega-investments by multinationals in the mining, natural gas and oil industries. The major tertiary institutions, of which Eduardo Mondlane University is one, currently have academic degrees with focus either in occupational or environmental safety. There is also a proliferation of short-term training courses in $\mathrm{OSH}$, given in collaboration with international organisations such as the South African National Occupational Safety Association (NOSA) and Bureau Veritas, among others. Some technical school courses cover basic levels of OSH; these are short duration offerings to help international consultants in these disciplines. 